\title{
Interaction of staphylococcal toxic shock syndrome toxin-1 and enterotoxin A on T cell proliferation and TNF secretion in human blood mononuclear cells
}

Monica L De Boer PhD ${ }^{1}$, Winnie WS Kum PhD ${ }^{1}$, Anthony W Chow MD FRCPC FACP ${ }^{1,2,3}$

\begin{abstract}
ML De Boer, WWS Kum, AW Chow. Interaction of staphylococcal toxic shock syndrome toxin-1 and enterotoxin A on $\mathrm{T}$ cell proliferation and TNF $\alpha$ secretion in human blood mononuclear cells. Can J Infect Dis 1999;10(6):403-409.
\end{abstract}

BACKGROUND: The majority of menstrual toxic shock syndrome (MTSS) cases are caused by a single clone of Staphylococcus aureus that produces both toxic shock syndrome toxin-1 (TSST-1) and staphylococcal enterotoxin A (SEA). OBJECTIVE: To determine whether the two superantigens interact to cause an enhancement of biological activity in human peripheral blood mononuclear cells (PBMCs).

DESIGN: PBMCs from nine healthy donors were stimulated with TSST-1 or SEA, either alone or in combination at their minimum effective concentrations.

SETTING: In vitro study.

INTERVENTIONS: Human PBMCs were stimulated in vitro with TSST-1 $(1 \mathrm{pg} / \mathrm{mL}), \mathrm{SEA}(0.1 \mathrm{pg} / \mathrm{mL})$ or combination for 20 to $72 \mathrm{~h}$. Mitogenic response was determined by $\left[{ }^{3} \mathrm{H}\right]$-thymidine incorporation. PBMC culture supernatants were assayed for the presence of tumour necrosis factor-alpha (TNF ), interleukin (IL)-1 and IL- 6 by ELISA.

MAIN RESULTS: The combination of TSST-1 and SEA induced significantly greater mitogenesis in human PBMCs compared with either toxin alone ( $\mathrm{P}<0.05$, paired Student's $t$ test, two-tailed). Similarly, the production of TNF in culture supernatants was significantly greater in the combination of TSST-1 and SEA compared with either TSST-1 or SEA alone $(\mathrm{P}<0.05)$. In contrast, no enhancement in the levels IL-1 or IL-6 was observed.

CONCLUSIONS: These data suggest that the co-production of TSST- 1 and SEA by $S$ aureus may provide some biological advantage to the organism throughs an enhanced effect of these superantigens on T cell activation and TNF secretion.

Key Words: Cytokines; Mitogenic response; Staphylococcal enterotoxin A; Toxic shock syndrome toxin-1

Pour le résumé, voir page suivante

\footnotetext{
Presented in part at the International Congress of Chemotherapy, July 19, 1995, Montreal, Quebec

${ }^{1}$ Division of Infectious Diseases, Departments of Medicine, ${ }^{2}$ Microbiology and Immunology, University of British Columbia; the Canadian Bacterial Diseases Network; ${ }^{3}$ Vancouver Hospital and Health Sciences Centre, Vancouver, British Columbia

Correspondence and reprints: Dr Anthony W Chow, Division of Infectious Diseases, Vancouver Hospital and Health Sciences Centre, 2733 Heather Street, Vancouver, British Columbia V5Z 3J5. Telephone 604-875-4148, fax 604-875-4013, e-mail tonychow@interchange.ubc.ca
}

Received for publication August 31, 1998. Accepted February 25, 1999 


\title{
Interaction de la toxine-1 et de l'entérotoxine A staphylococciques du syndrome de choc toxique sur la prolifération des cellules T et sur la sécrétion du TNF $\alpha$ dans les cellules mononucléaires du sang humain
}

\begin{abstract}
HISTORIQUE : La plupart des cas de syndrome de choc toxique en rapport avec les menstruations sont causés par un simple clone de Staphylococcus aureus qui produit à la fois la toxine-1 du choc toxique (TSST-1) et l'entérotoxine A staphylococcique (SEA).

OBJECTIF : Déterminer si les deux superantigènes interagissent pour entraîner une hausse de l'activité biologique dans les cellules mononucléaires du sang périphérique (CMSP) humain.

MODÈLE : Des CMSP de neuf donneurs sains ont été stimulées avec la TSST-1 ou la SEA, soit seules ou en combinaison, à leurs concentrations minimales produisant un effet.

CONTEXTE : Étude in vitro.

INTERVENTIONS : Des CMSP humains ont été stimulées in vitro avec la TSST-1 (1pg/mL), la SEA (0,1 pg/mL) ou avec les deux toxines combinées pendant 20 à 72 heures. Une réponse mitogène a été déterminée par l'incorporation de thymidine ${ }^{3} \mathrm{H}$. Les surnageants de culture des CMSP ont subi un dosage par la méthode ELISA visant à rechercher le TNF (tumour necrosis factor-alpha) et l'interleukine (IL) 1 et IL 6.

PRINCIPAUX RÉSULTATS : La combinaison de la TSST-1 et de la SEA a induit une activation mitotique nettement plus importante dans les CMSP humains comparativement à chaque toxine utilisée isolément ( $\mathrm{p}<0,05$, test $t$ apparié de Student, bilatéral). De la même manière, la production de TNF dans les surnageants de culture était nettement supérieure dans la combinaison TSST-1 et SEA comparativement à chaque toxine utilisée isolément $(\mathrm{p}<0,05)$. Par contre, on n'a pas observé une augmentation des niveaux d'IL 1 ou d'IL 6.

CONCLUSIONS : Ces données permettent de croire que la coproduction de la TSST-1 et de la SEA par $S$. aureus pourrait fournir un certain avantage biologique à l'organisme par le biais d'une augmentation de l'effet de ces superantigènes sur l'activation des cellules T et la sécrétion du TNF.
\end{abstract}

$\mathrm{S}$ taphylococcal toxic shock syndrome (TSS) is a severe multisystem disease characterized by fever, diffuse skin rash followed by desquamation, hyperemia of the mucous membranes and hypotension or shock. Although initially described primarily in menstruating women in association with tampon use, nonmenstrual cases are increasingly recognized (1). Earlier studies by the authors $(2,3)$ and others $(4,5)$ strongly implicated TSS toxin-1 (TSST-1) as the primary cause of TSS. Apart from TSST-1, the staphylococcal enterotoxins are also strongly linked to TSS (6). By using ELISA and DNA probes, we have examined the production of TSST-1, staphylococcal enterotoxin A (SEA), staphylococcal enterotoxin B (SEB) and staphylococcal enterotoxin C (SEC) in the culture supernatants from 350 Staphylococcus aureus isolates recovered from Vancouver cases of menstrual TSS (MTSS), nonmenstrual TSS (NMTSS), non-TSS $S$ aureus infections and asymptomatic carriers $(1,7,8)$. Interestingly, SEA was commonly coproduced with TSST-1, and this toxin combination was significantly more prevalent in MTSS than in other groups (75\% in MTSS compared with $32 \%$ in NMTSS and $25 \%$ in non-TSS-associated $S$ aureus infections) (7). Epidemiological typing by multilocus enzyme electrophoresis also revealed that MTSS isolates were primarily from a single $S$ aureus clone that produced both TSST- 1 and SEA $(7,9)$. Both TSST- 1 and SEA belong to a related family of superantigens that induce massive $T$ cell proliferation via specific $V$ determinants of the $\mathrm{T}$ cell receptor (TCR), and stimulate the release of various proinflammatory cytokines by human, murine and bovine lymphoid cells (10-13). These biological effects are believed to play a central role in the pathogenesis of superantigenmediated shock (14-16). Because MTSS is associated with a predominant clone of $S$ aureus, which produces both TSST-1 and SEA, we hypothesized that coproduction of these toxins might enhance the biological activities of either toxin alone. To test this hypothesis, we examined the interaction of purified TSST- 1 and SEA, alone or in combination, on the induc- tion of mitogenic response and cytokine secretion of human peripheral blood mononuclear cells (PBMCs) from healthy donors. To our knowledge, this is the first study to examine the effects of superantigen coproduction on the induction of various biological responses believed to be important in the pathogenesis of staphylococcal TSS.

\section{MATERIALS AND METHODS}

Purification of TSST- 1 and SEA: TSST-1 was purified from culture supernatants of $S$ aureus MN8 by preparative isoelectric focusing and chromatofocusing as previously described (17). SEA was purchased from Toxin Technology (Sarasota, Florida) and further purified by chromatofocusing using a pH 6 to 8 gradient polybuffer exchanger (PBE 94; Pharmacia Fine Chemicals, Uppsala, Sweden). The purity of TSST-1 and SEA preparations was verified by the presence of a single band of approximately $22 \mathrm{kD}$ and approximately $28 \mathrm{kD}$, respectively, following SDS-PAGE or immunoblotting with polyclonal antisera (17). Purification of human PBMC: Fresh human PBMCs were obtained from healthy donors by the method previously described (11). In brief, cells were obtained by centrifugation of leukopheresis packs over Histopaque 1.077 (Sigma Chemical $\mathrm{Co}$, St Louis, Missouri). Mononuclear cells at the interface were washed with Hank's balanced salt solution before being separated into $\mathrm{T}$ cells and non- $\mathrm{T}$ cell populations by rosetting with sheep erythrocytes. Monocytes were purified from B lymphocytes by density gradient centrifugation over Percoll (Pharmacia Fine Chemicals, Dorval, Quebec). For isolating purified human T lymphocytes, E-rosetted cells were treated with ammonium chloride to remove sheep erythrocytes, washed three times with Hank's balanced salt solution and suspended in RPMI 1640 (StemCell Technologies Inc, Vancouver, British Columbia) supplemented with $10 \%$ heat inactivated $\left(56^{\circ} \mathrm{C}\right.$, 30 mins) fetal calf serum (Gibco/BRL Life Technologies Inc, Gaithersburg, Maryland), $2 \mathrm{mM}$ L-glutamine, $25 \mathrm{mM}$ Hepes buffer and $10 \mathrm{~g} / \mathrm{mL}$ polymyxin B sulphate. 


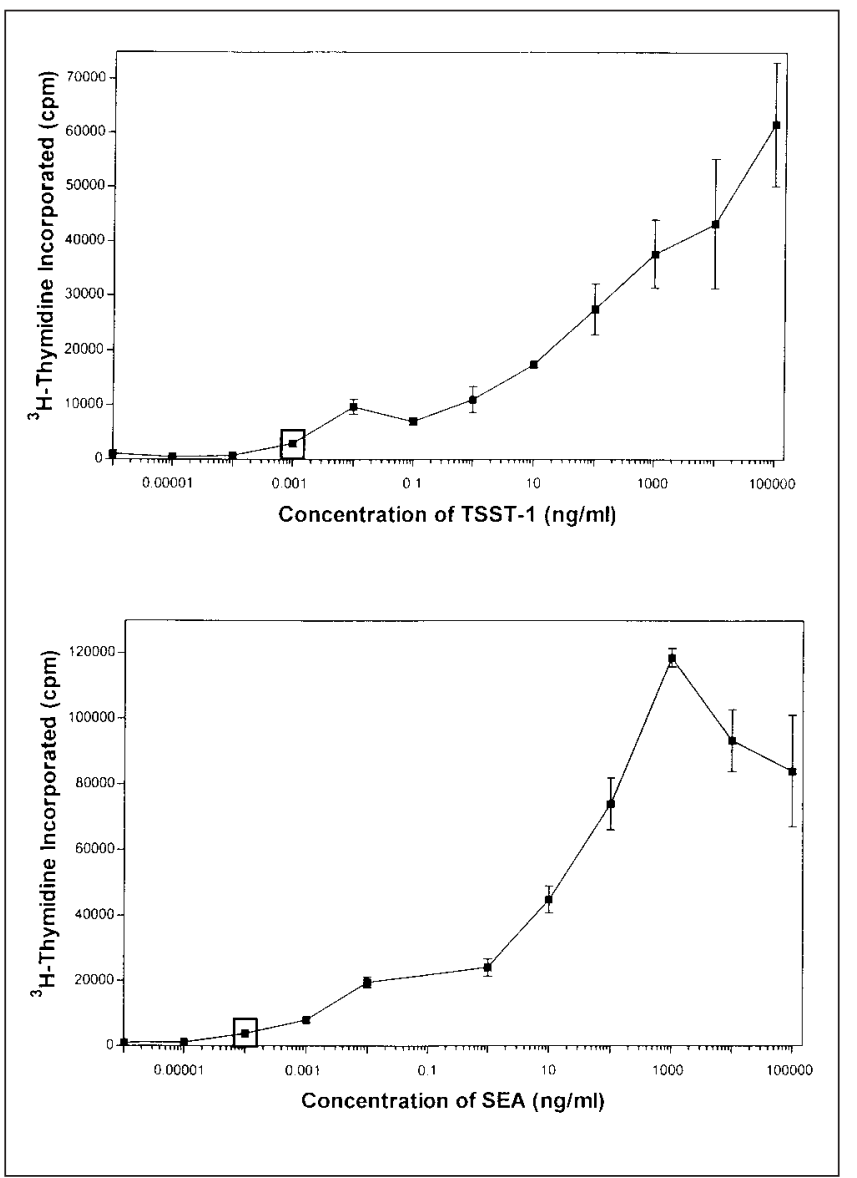

Figure 1) Dose-response relationship of different concentrations of purified toxic shock syndrome toxin-1 (TSST-1) (top) or staphylococcal enterotoxin A (SEA) (bottom) on the mitogenic response of human peripheral blood mononuclear cells from a healthy donor following stimulation for $72 \mathrm{~h}$. The mitogenic response was measured by $\left.{ }^{3} \mathrm{H}\right]$-thymidine incorporation. Each value is presented as the mean \pm SEM for triplicate determinations. The minimum effective concentrations of TSST-1 and SEA used for subsequent mitogenesis assays are indicated by the boxes

Mitogenicity assay: Mitogenesis of human PBMCs stimulated by TSST-1 or SEA was assessed by $\left[{ }^{3} \mathrm{H}\right]$-thymidine incorporation as previously described (17). A 1:1 ratio of T cells to monocytes $\left(3 \times 10^{5}\right.$ cells/well) in supplemented RPMI 1640 were cultured in $0.2 \mathrm{~mL}$ volumes with various concentrations of TSST-1, SEA, or combination for three days at $37^{\circ} \mathrm{C}, 5 \%$ carbon dioxode in 96-well round-bottom plates (Falcon Labware, Becton-Dickinson Canada Inc, Mississauga, Ontario). Cells were pulsed with $1 \mathrm{Ci}$ of $\left[{ }^{3} \mathrm{H}\right]$-thymidine $(6.7 \mathrm{Ci} / \mathrm{mmol}$; ICN Flow Laboratories, Irvine, California) $18 \mathrm{~h}$ before completion of incubation, and harvested onto glass-fibre filter paper with an automatic harvester (Skatron, Sterling, Virginia). Samples were counted in a liquid scintillation counter (LS1800, Beckman, Mississauga, Ontario).

Cytokine assays for tumour necrosis factor-alpha, interleukin-1ß and interleukin-6: A 1:1 ratio of $\mathrm{T}$ cells to monocytes $\left(2 \times 10^{6}\right.$ cells/well $)$ in supplemented RPMI 1640 were cultured in $1.0 \mathrm{~mL}$ volumes in conjunction with various concentrations of TSST- 1 , SEA or combination at $37^{\circ} \mathrm{C}$ and $5 \%$

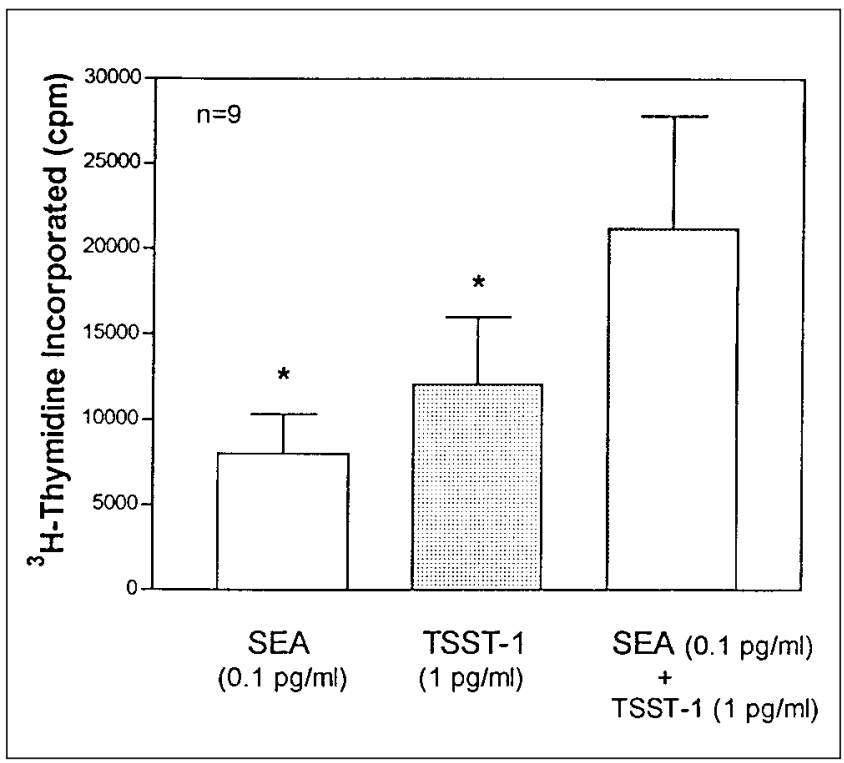

Figure 2) Mitogenic response of human peripheral blood mononuclear cells from nine healthy donors stimulated with toxic shock syndrome toxin-1 (TSST-1), staphylococcal enterotoxin A (SEA) or their combination for $72 h$. Each value is presented as the mean \pm SEM from a minimum of quadruplicate determinations. *Significantly difference from the combination of TSST-1 and SEA (P<0.05; paired Student's $\mathrm{t}$ test, two-tailed)

carbon dioxide in 24-well culture plates (Becton-Dickinson). After approximately $20 \mathrm{~h}$, supernatants were harvested by centrifugation at $800 \mathrm{~g}$ for $5 \mathrm{mins}$, and stored at $-70^{\circ} \mathrm{C}$ until analysis. Tumour necrosis factor-alpha (TNF ), interleukin (IL)-1 , and IL- 6 present in the culture supernatants were assayed by ELISA previously developed in the authors' laboratory (17). The sensitivity limits for detection were $250 \mathrm{pg} / \mathrm{mL}$ for TNF , $500 \mathrm{pg} / \mathrm{mL}$ for IL-1ß, and $625 \mathrm{pg} / \mathrm{mL}$ for IL-6.

Statistical analyses: All quantitative data were expressed as means \pm standard error of the mean (SEM). Differences in mitogenic responses and cytokine secretion between different groups were compared using the Student's $t$ test for paired samples (two-tailed). $\mathrm{P}<0.05$ was considered significant.

\section{RESULTS}

Minimum effective dose of TSST-1 and SEA for inducing mitogenesis in human PBMCs: PBMCs (1:1 ratio of T cells to monocytes) from one healthy donor were stimulated with various concentrations of TSST- 1 and SEA $(0.001 \mathrm{pg} / \mathrm{mL}$ to $100 \mathrm{~g} / \mathrm{mL}$ ) to generate dose-response curves for mitogenesis (Figure 1). This was performed to select a minimum effective concentration of TSST-1 and SEA for the interaction studies. The concentration range of the dose response to TSST- 1 and SEA observed in this donor was similar to that observed by other investigators (17-20), although the amplitude of the proliferative responses varied from one subject to another (18). Based on these dose-response curves, $1 \mathrm{pg} / \mathrm{mL}$ of TSST- 1 and $0.1 \mathrm{pg} / \mathrm{mL}$ of SEA, respectively, were chosen for further study of the mitogenic responses in human PBMC. Two higher doses of TSST-1 (10 pg/mL and $100 \mathrm{pg} / \mathrm{mL})$ were also tested in some cases. 
TABLE 1

Induction of tumour necrosis factor-alpha (TNF $\alpha$ ) interleukin (IL)-1 and IL-6 in culture supernatants of human peripherial blood mononuclear cells (PBMCs) from healthy donors followng stimulation with TSST-1 and SEA

\begin{tabular}{|c|c|c|c|c|c|c|}
\hline \multirow[b]{2}{*}{ Donor } & \multicolumn{2}{|c|}{$\mathrm{TNF} \alpha(\mathrm{pg} / \mathrm{mL})$} & \multicolumn{2}{|c|}{ IL-1 (pg/mL) } & \multicolumn{2}{|c|}{ IL-6 (pg/mL) } \\
\hline & TSST-1 (10pg/mL) & SEA $(1 \mathrm{pg} / \mathrm{mL})$ & TSST-1 $(10 \mathrm{pg} / \mathrm{mL})$ & SEA $(1 \mathrm{pg} / \mathrm{mL})$ & TSST-1 (10pg/mL) & SEA $(1 \mathrm{pg} / \mathrm{mL})$ \\
\hline 1 & 114945 & 153963 & 11,850750 & $14,250 \quad 210$ & 10855 & 127020 \\
\hline 2 & 9145 & UD & 18,0001380 & 11,130 1110 & 66681 & 984267 \\
\hline 3 & 101032 & UD & UD & UD & 2601201 & UD \\
\hline 4 & UD & UD & UD & UD & UD & UD \\
\hline 5 & 117832 & 126672 & UD & UD & UD & UD \\
\hline 6 & NT & NT & UD & UD & UD & UD \\
\hline 7 & NT & NT & 93664 & 6032 & 6737 & UD \\
\hline 8 & NT & NT & $14,130 \quad 450$ & $3725 \quad 5$ & 29935 & 202020 \\
\hline
\end{tabular}

Human PBMCs from eight donors were stimulated with TSST-1 $(10 \mathrm{pg} / \mathrm{mL})$ and SEA (1 pg/mL) for approximately $20 \mathrm{~h}$. TNFa, IL-1 and IL-6 in the culture supernatants were measured by ELISA. Sensitivity limits of detection were 250, 500, and $625 \mathrm{pg} / \mathrm{ml}$, respectively. Results for each donor are expressed as the mean SEM cytokine concentration $(\mathrm{pg} / \mathrm{mL})$ in duplicate determinations. NT Not tested; UD Undetectable

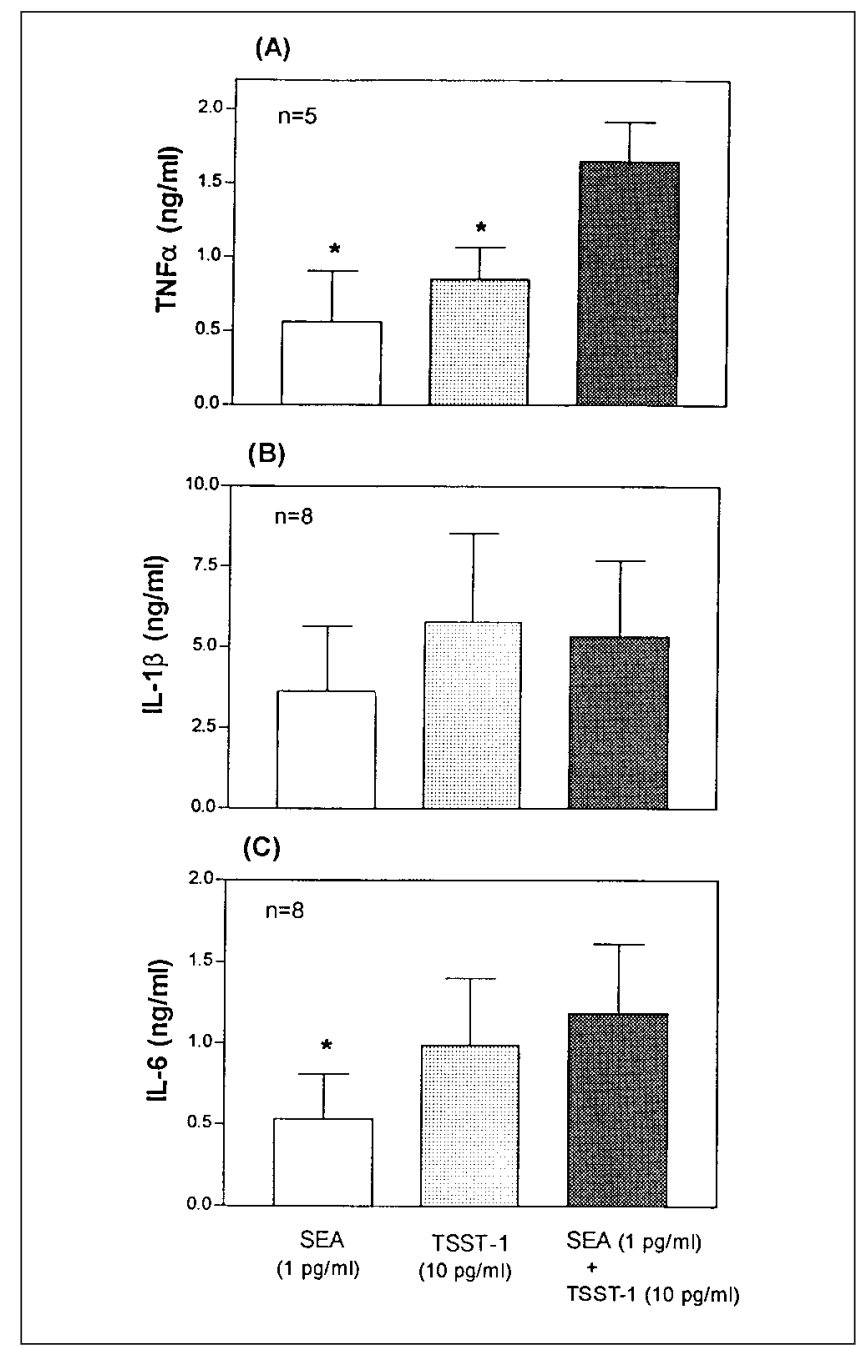

Figure 3) Induction of tumour necrosis factor-alpha (TNF $\alpha$ ), interleukin (IL)-1 in culture supernatant of human peripherial blood mononuclear cells from healthy donors after stimulation with toxic shock syndrome toxin-1 (TSST-1), staphylococcal enterotoxin A (SEA) or their combination for approximately $20 \mathrm{~h}$. Each value represents the mean \pm SEM of duplicate derminations. *Significantly different from the combination of TSST-1 and SEA $(P<0.05$, paired Student's t test, two-tailed)
Interaction of TSST-1 and SEA on mitogenesis of human PBMC: The mitogenic response of human PBMCs to the combination of TSST-1 at $1.0 \mathrm{pg} / \mathrm{mL}$ and SEA at $0.1 \mathrm{pg} / \mathrm{mL}$ from nine healthy donors was significantly greater than either toxin alone ( $\mathrm{P}<0.05$, paired Student's $t$ test, two-tailed) (Figure 2 ). In addition, PBMCs from three donors simulated with TSST-1 at $10 \mathrm{pg} / \mathrm{mL}$ and at $100 \mathrm{pg} / \mathrm{mL}$, each in combination with 0.1 $\mathrm{pg} / \mathrm{mL}$ SEA, also exhibited significantly greater $\mathrm{T}$ cell mitogenesis than either toxin alone (data not shown). The increased mitogenic effect appeared to be additive rather than synergistic, because the mean proliferative response observed upon coincubation with TSST-1 and SEA did not significantly exceed the sum of the proliferative response with either toxin alone.

Minimum effective dose of TSST-1 and SEA on cytokine secretion from human PBMCs: The dose responses of human PBMCs to various concentrations of TSST- 1 and SEA (ranging from 0.001 to $1 \mathrm{~g} / \mathrm{mL}$ ) in the induction of TNF , IL-1ß, and IL-6 were studied in one healthy donor. Although dosedependent effects of TSST-1- and SEA-induced TNF and IL-6 production were observed with this donor (data not shown), IL-1 B was detected only at the highest concentration of TSST-1 and SEA tested (1 $\mathrm{g} / \mathrm{mL})$. In light of this, and the inherent variability in cytokine induction from different donors $(21,22)$, the minimum effective dose of TSST- 1 and SEA, chosen arbitrarily for further study of cytokine secretion in human PBMCs, were $10 \mathrm{pg} / \mathrm{mL}$ and 1.0 or $10 \mathrm{pg} / \mathrm{mL}$, respectively.

Interaction of TSST- 1 and SEA on TNF $\alpha$, IL- $1 \beta$ and IL- 6 secretion in human PBMCs: PBMCs (1:1 ratio of T cells to monocytes) of eight healthy donors were stimulated with TSST-1 $(10 \mathrm{pg} / \mathrm{mL})$ and SEA $(1 \mathrm{pg} / \mathrm{mL})$, either alone or in combination. Considerable intersubject variability in cytokine responses was observed (Table 1). A significant increase in TNF was observed in the culture supernatants harvested from five donors stimulated with the combination of TSST-1 and SEA (1.65 $0.27 \mathrm{ng} / \mathrm{mL}$ ) compared with either TSST-1 alone (0.85 $0.22 \mathrm{ng} / \mathrm{mL}, \mathrm{P}<0.05$, paired $t$ test, two-tailed), or SEA alone $(0.560 .35 \mathrm{ng} / \mathrm{mL}, \mathrm{P}<0.05)$ (Figure $3 \mathrm{~A})$. In contrast with TNF , the induction of IL-1B from eight donors stimulated with the combination (5.34 $2.4 \mathrm{ng} / \mathrm{mL}$ ) was not significantly 
greater than with TSST-1 alone (5.77 $2.8 \mathrm{ng} / \mathrm{mL}$ ) or SEA alone (3.65 $2.0 \mathrm{ng} / \mathrm{mL}$ ) (Figure 3B). Increasing the concentration of SEA to $10 \mathrm{pg} / \mathrm{mL}$ did not alter the results (data not shown). Similarly, the induction of IL- 6 from eight donors stimulated with the combination (1.19 $0.43 \mathrm{ng} / \mathrm{mL})$ was not significantly greater than with TSST-1 alone (0.99 $0.41 \mathrm{ng} / \mathrm{mL})$, although a significant increase was observed in comparison with SEA alone $(0.530 .28 \mathrm{ng} / \mathrm{mL} ; \mathrm{P}<0.05)$ (Figure $3 \mathrm{C}$ ). Again, increasing the concentration of SEA to $10 \mathrm{pg} / \mathrm{mL}$ did not change the results (data not shown).

\section{DISCUSSION}

The objective of our study was to determine if the combination of minimum effective concentrations of TSST-1 and SEA would induce greater $\mathrm{T}$ cell proliferation and cytokine secretion from human PBMCs with compared either toxin alone. This might be suspected because TSST-1 and SEA have similar biological activities, and both bind to MHC class II molecules on human PBMCs $(23,24)$, an event critical for both T cell mitogenesis and cytokine secretion (11,25-27). Furthermore, because TSST- 1 and SEA share a common MHC class II receptor in human PBMCs (28-30), a greater response in mitogenesis or cytokine secretion, at minimum effective concentrations, could be expected from the combination of these two toxins rather than with either toxin alone. Our finding that the coincubation of SEA with TSST-1 induced significantly greater $\mathrm{T}$ cell proliferation and TNF secretion supports this notion. The enhanced effects of these toxins in combination are relevant because TSS-associated $S$ aureus frequently co-produce both TSST- 1 and SEA $(7,31,32)$ and because these two biological activities are believed to be pivotal to the pathogenesis of TSS $(15,16)$. However, one must be cautious in extrapolating these in vitro results to the clinical setting because the precise amount of TSST-1 and SEA produced in vivo by $S$ aureus during TSS is not known.

In contrast with TNF induction, we were unable to demonstrate an enhancement in either IL-1B or IL- 6 production by the toxin combination compared with both TSST-1 and SEA alone. There are a number of possible explanations for this apparent disparity. First, it is likely that suboptimal concentrations of TSST-1 and SEA were used for some of the donors studied. Ideally, a dose-response curve for IL-1B and IL-6 induction should be determined for each PBMC donor, so that the minimum effective dose of TSST- 1 and SEA could be more precisely defined for each individual donor. Secondly, the secretion of IL-1B and IL- 6 in PBMC is known to appear later than TNF after superantigen stimulation (16). Because cytokine secretion in our study was determined at approximately $20 \mathrm{~h}$ after stimulation, there may not have been sufficient time for IL- $1 B$ and IL- 6 synthesis and secretion to occur in the PBMCs of some donors in contrast with TNF . In support of this, IL-1ß was below the limits of detection in four of eight culture supernatants, while IL-6 was undetectable in three of eight donors (Table 1). However, because these cytokines appear to be differentially regulated via distinct signal transduction pathways (33-35), it would not be totally surprising if this apparent disparity in cytokine secretion between TNF and the other cytokines was still observed when tested under more optimal conditions. Whether the different cytokine activation pathways induced by these toxins are related to the unique MHC Class II-binding sites of these toxins (36-38) is not known.

Considerable intersubject variability in cytokine secretion patterns was observed in our healthy donors following superantigen stimulation, as has been documented by others $(21,22,39)$. For example, among the eight donors examined for cytokine secretion in the current study, the amount of IL- $1 B$ induced with $10 \mathrm{pg} / \mathrm{mL}$ of TSST- 1 ranged from less than 500 to $18,000 \mathrm{pg} / \mathrm{mL}$, whereas IL-6 levels ranged from less than 625 to $2935 \mathrm{pg} / \mathrm{mL}$ (Table 1). A similar finding was observed following stimulation with $1 \mathrm{pg} / \mathrm{mL}$ of SEA. Donor 1 produced high amounts of all three cytokines in response to both TSST- 1 and SEA, whereas donor 4 did not produce any detectable cytokine in response to either TSST-1 or SEA. In general, donor PBMCs that did not respond to TSST-1 (eg, donors 4, 5 and 6) also did not respond to SEA in the secretion of identical cytokines. Several factors, including isotypic and allelic polymorphism of MHC Class II in different subjects, could account for the variations observed in the secretion of different cytokines by the same donor or the same cytokine by different donors. First, different superantigens preferentially bind to distinct MHC class II isotypes $(40,41)$ and alleles $(36,41)$, thereby possibly leading to variability in the induction of different cytokines in the same individual. In this regard, the activation of certain $T$ cell subsets by SEA was found to have an influence on the type of cytokine released from human monocytes $(42,43)$. The finding that human TNF genes are linked to the MHC gene cluster on chromosome 6 (44) also supports the concept that genetic factors may regulate the cytokine response, at least for TNF . Genetic factors may also provide an explanation for the observation that some individuals appear to be consistently high or low cytokine producers (21). Variation in the VB determinant for the TCR repertoire among different individuals may also account for some intersubject variability in cytokine responses to different superantigens (10).

\section{CONCLUSIONS}

The combination of TSST-1 and SEA induces a significantly greater mitogenic response and TNF secretion in human PBMCs compared with stimulation with either toxin alone. Whether these in vitro observations also occur in vivo and whether the coproduction of TSST-1 and SEA in TSSassociated $S$ aureus renders this strain more virulent than another that produces only TSST-1 or SEA clearly warrant further investigation.

ACKNOWLEDGEMENTS: We thank the nursing staff at the Cell Separator Unit at the Vancouver Hospital and Health Sciences Centre for supplying the leukopheresis packs from healthy donors, and Dr KB Laupland for optimizing the IL-6 immunoassay. This study was supported in part by a grant from the Medical Research Council of Canada to AWC (MT-7630). 


\section{REFERENCES}

1. Kain KC, Schulzer M, Chow AW. Clinical spectrum of nonmenstrual toxic shock syndrome (TSS): comparison with menstrual TSS by multivariate discriminant analyses. Clin Infect Dis $1993 ; 16: 100-6$.

2. Rosten PM, Bartlett KH, Chow AW. Serologic responses to toxic shock syndrome (TSS) toxin-1 in menstrual and nonmenstrual TSS. Clin Invest Med 1988;11:187-92.

3. Whiting JL, Rosten PM, Chow AW. Determination by Western blot (immunoblot) of seroconversions to toxic shock syndrome (TSS) toxin 1 and enterotoxin A, B, or C during infection with TSS- and non-TSS-associated Staphylococcus aureus. Infect Immun 1989;57:231-4.

4. Schlievert PM, Shands KN, Dan BB, Schmid GP, Nishimura RD. Identification and characterization of an exotoxin from Staphylococcus aureus associated with toxic-shock syndrome. J Infect Dis 1981;143:509-16.

5. Stolz SJ, Davis JP, Vergeront JM, et al. Development of serum antibody to toxic shock toxin among individuals with toxic shock syndrome in Wisconsin. J Infect Dis 1985;151:883-9.

6. See RH, Chow AW. Microbiology of TSS: overview. Rev Infect Dis 1989;11(Suppl 1):S55-60.

7. Chang AH, Musser JM, Chow AW. A single clone of $S$. aureus which produces both TSST-1 and SEA causes the majority of menstrual toxic shock syndrome. Clin Res 1991;39:36A. (Abst)

8. Lee VT, Chang AH, Chow AW. Detection of staphylococcal enterotoxin B among toxic shock syndrome (TSS)- and non-TSS-associated Staphylococcus aureus isolates. J Infect Dis 1992;166:911-5

9. Musser JM, Schlievert PM, Chow AW, et al. A single clone of Staphylococcus aureus causes the majority of cases of toxic shock syndrome. Proc Natl Acad Sci USA 1990;87:225-9.

10. Drake CG, Kotzin BL. Superantigens: Biology, immunology, and potential role in disease. J Clin Immunol 1992;12:149-62.

11. See RH, Kum WWS, Chang AH, Goh SH, Chow AW. Induction of tumor necrosis factor and interleukin-1 by purified staphylococcal toxic shock syndrome toxin 1 requires the presence of both monocytes and T lymphocytes. Infect Immun 1992;60:2612-8

12. Uchiyama T, Kamagata Y, Yan XJ, et al. Relative strength of the mitogenic and interleukin-2-production-inducing activities of staphylococcal exotoxins presumed to be causative exotoxins of toxic shock syndrome: toxic shock syndrome toxin-1 and enterotoxins A, B and C to murine and human T cells. Clin Exp Immunol 1989;75:239-44.

13. Yokomizo Y, Mori Y, Shimoji Y, et al. Proliferative response and cytokine production of bovine peripheral blood mononuclear cells induced by the superantigens staphylococcal enterotoxins and toxic shock syndrome toxin-1. J Vet Med Sci 1995;57:299-305

14. Marrack P, Kappler J. The staphylococcal enterotoxins and their relatives. Science 1990;248:705-11.

15. Miethke T, Duschek K, Wahl C, Heeg K, Wagner H. Pathogenesis of the toxic shock syndrome: T cell mediated lethal shock caused by the superantigen TSST-1. Eur J Immunol 1993;23:1494-500.

16. Miethke T, Wahl C, Regele D, Gaus H, Heeg K, Wagner H. Superantigen mediated shock: a cytokine release syndrome. Immunobiology 1993; 189:270-84.

17. Kum WWS, Laupland KB, See RH, Chow AW. Improved purification and biologic activities of staphylococcal toxic shock syndrome toxin 1. J Clin Microbiol 1993;31:2654-60.

18. Calvano SE, Quimby FW, Antonacci AC, Reiser RF, Bergdoll MS, Dineen P. Analysis of the mitogenic effects of toxic shock toxin on human peripheral blood mononuclear cells in vitro. Clin Immunol Immunopath 1984;33:99-110.

19. Poindexter NJ, Schlievert PM. Toxic-shock-syndrome toxin 1-induced proliferation of lymphocytes: comparison of the mitogenic response of human, murine, and rabbit lymphocytes. J Infect Dis 1985;151:65-72.

20. Langford MP, Stanton GJ, Johnson HM. Biological effects of staphylococcal enterotoxin A on human peripheral lymphocytes. Infect Immun 1978;22:62-8.

21. Endres S, Ghorbani R, Lonnemann G, van der Meer JWM, Dinarello CA. Measurement of immunoreactive interleukin-1 beta from human mononuclear cells: optimization of recovery, intrasubject consistency, and comparison with interleukin-1 alpha and tumor necrosis factor. Clin Immunol Immunopath 1988;49:424-38.

22. Schindler R, Mancilla J, Endres S, Ghorbani R, Clark SC, Dinarello CA. Correlations and interactions in the production of interleukin-6 (IL-6), IL-1, and tumor necrosis factor (TNF) in human mononuclear cells: IL-6 suppresses IL-1 and TNF. Blood 1990;75:40-7.

23. Mollick JA, Cook RG, Rich RR. Class II MHC molecules are specific receptors for staphylococcus enterotoxin A. Science 1989;244:817-20.

24. Scholl P, Diez A, Mourad W, Parsonnet J, Geha RS, Chatila T. Toxic shock syndrome toxin 1 binds to major histocompatability complex class II molecules. Proc Natl Acad Sci USA 1989;86:4210-4.

25. Akatsuka H, Imanishi K, Inada K, Yamashita H, Yoshida M, Uchiyama T. Production of tumour necrosis factors by human $\mathrm{T}$ cells stimulated by a superantigen, toxic shock syndrome toxin-1. Clin Exp Immunol 1994;96:422-6.

26. Matsuyama S, Koide Y, Yoshida TO. HLA class II moleculemediated signal transduction mechanism responsible for the expression of interleukin-1 beta and tumor necrosis factor-alpha genes induced by a staphylococcal superantigen. Eur J Immunol 1993;23:3194-202.

27. Labrecque N, Thibodeau J, Mourad W, Sekaly R-P. T cell receptor-major histocompatibility complex class II interaction is required for the $\mathrm{T}$ cell response to bacterial superantigens. J Exp Med 1994;180:1921-9.

28. See RH, Krystal G, Chow AW. Binding competition of toxic shock syndrome toxin 1 and other staphylococcal exoproteins for receptors on human peripheral blood mononuclear cells. Infect Immun 1990;58:2392-6.

29. See RH, Krystal G, Chow AW. Receptors for toxic shock syndrome toxin-1 and staphylococcal enterotoxin A on human blood monocytes. Can J Microbiol 1992;38:937-44.

30. Bavari S, Ulrich RG. Staphylococcal enterotoxin A and toxic shock syndrome toxin compete with CD4 for human major histocompatibility complex class II binding. Infect Immun 1995;63:423-9.

31. Crass BA, Bergdoll MS. Toxin involvement in toxic shock syndrome. J Infect Dis 1986;153:918-26.

32. Lehn N, Schaller E, Wagner H, Kronke M. Frequency of toxic shock syndrome toxin- and enterotoxin- producing clinical isolates of Staphylococcus aureus. Eur J Clin Microbiol Infect Dis 1995; 14:43-6.

33. See RH, Chow AW. Staphylococcal toxic shock syndrome toxin 1-induced tumor necrosis factor alpha and interleukin-1 beta secretion by human peripheral blood monocytes and $\mathrm{T}$ lymphocytes is differentially suppressed by protein kinase inhibitors. Infect Immun 1992;60:3456-9.

34. Trede NS, Morio T, Scholl PR, Geha RS, Chatila T. Early activation events induced by the staphylococcal superantigen toxic shock syndrome toxin-1 in human peripheral blood monocytes. Clin Immunol Immunopath 1994;70:137-44.

35. See RH, Krystal G, Chow AW. TSST-1 and staphylococcal enterotoxins induce distinct patterns of protein phosphorylation in human monocytes. Clin Res 1992;40:53A. (Abst)

36. Labrecque N, Thibodeau J, Sekaly R-P. Interactions between staphylococcal superantigens and MHC class II molecules. Sem Immunol 1993;5:23-32.

37. Dowd JE, Karr RW, Karp DR. Functional activity of staphylococcal enterotoxin A requires interactions with both the alpha and beta chains of HLA-DR. Mol Immunol 1996;33:1267-74.

38. Hamad ARA, Herman A, Marrack P, Kappler JW. Monoclonal antibodies defining functional sites on the toxin superantigen staphylococcal enterotoxin B. J Exp Med 1994;180:615-21.

39. de Azavedo JC, Drumm A, Jupin C, Parant M, Alouf JE, Arbuthnott JP. Induction of tumour necrosis factor by staphylococcal toxic shock toxin 1. FEMS Microbiol Lett 1988; $1: 69-74$

40. Herrmann T, Accolla RS, MacDonald HR. Different staphylococcal enterotoxins bind preferentially to distinct major histocompatibility complex class II isotypes. Eur J Immunol 1989;19:2171-4 
41. Herman A, Croteau G, Sekaly R-P, Kappler J, Marrack P. HLA-DR alleles differ in their ability to present staphylococcal enterotoxins to T cells. J Exp Med 1990;172:709-17.

42. Fleischer B, Schrezenmeier H, Conradt P. T lymphocyte activation by staphylococcal enterotoxins: role of class II molecules and T cell surface structures. Cell Immunol 1989;120:92-101. 43. Gjorloff A, Fisher H, Hedlund G, et al. Induction of interleukin-1 in human monocytes by the superantigen staphylococcal enterotoxin A requires the participation of T cells. Cell Immunol 1991;137:61-71.

44. Spies T, Morton CC, Nedospasov SA, Fiers W, Pious D, Strominger JL. Genes for the tumor necrosis factors alpha and beta are linked to the human major histocompatibility complex. Proc Natl Acad Sci USA 1986;83:8699-702.

\section{CLINICAL VIGNETTE}

Continued from page 383

\section{DIAGNOSIS}

Sinus X-rays were performed (single view in Figure 2), which showed complete opacification of both maxillary sinuses, air fluid levels in both frontal sinuses, opacification of the ethmoid sinuses and a questionable air fluid level in the sphenoid sinus. A computed tomography scan of the sinuses and orbits with infusion showed the soft tissue swelling of the face without extension into the orbits. The nasal cavity was completely occluded, with uptake of radiocontrast into the nasal, ethmoid and maxillary mucosa. The computed tomographic scan also showed complete occlusion of the maxillary sinuses by hypodense material, and partial occlusion of the sphenoid and frontal sinuses as well. Air fluid levels were again seen in the frontal sinuses. A diagnosis of facial erysipelas secondary to pansinusitis was made.

The patient was started on intravenous meropenem (Merrem, AstraZeneca, Mississauga, Ontario) with gradual improvement in the fever and facial swelling over the next four days. No sinus lavage was felt to be indicated, due to the adequate response to antibiotics alone. Blood cultures were negative, and he was changed to oral amoxicillin/clavulanic acid (Clavulin, SmithKline Beecham, Oakville, Ontario) and discharged home on day 5. A follow-up visit with the otolaryngologists was arranged.

\section{DISCUSSION}

Facial erysipelas used to be the most common form of erysipelas, now much more common in the lower extremity. It is almost always caused by Streptococcus pyogenes, but may be produced by beta-hemolytic streptococci of other types (ie, groups $\mathrm{C}$ or $\mathrm{G}$ ), as well as other bacteria in more rare circumstances. Preceding skin trauma or portals of entry are common, but facial erysipelas may also be caused by extension of orofacial foci such as odontogenic infections. Sinus infections as a source of facial erysipelas, without orbital involvement, are quite rare. The exact microbial etiology of facial erysipelas when caused by an underlying sinusitis is unknown, but may be polymicrobial in nature. Cultures of erysipelas are infrequently positive, even if performed by 'leading edge aspiration' of the rash. Bacteremia occurs less than $5 \%$ of the time. Therapy usually consists of antistreptococcal antibiotics (unless the condition is suspected to be caused by a polymicrobial

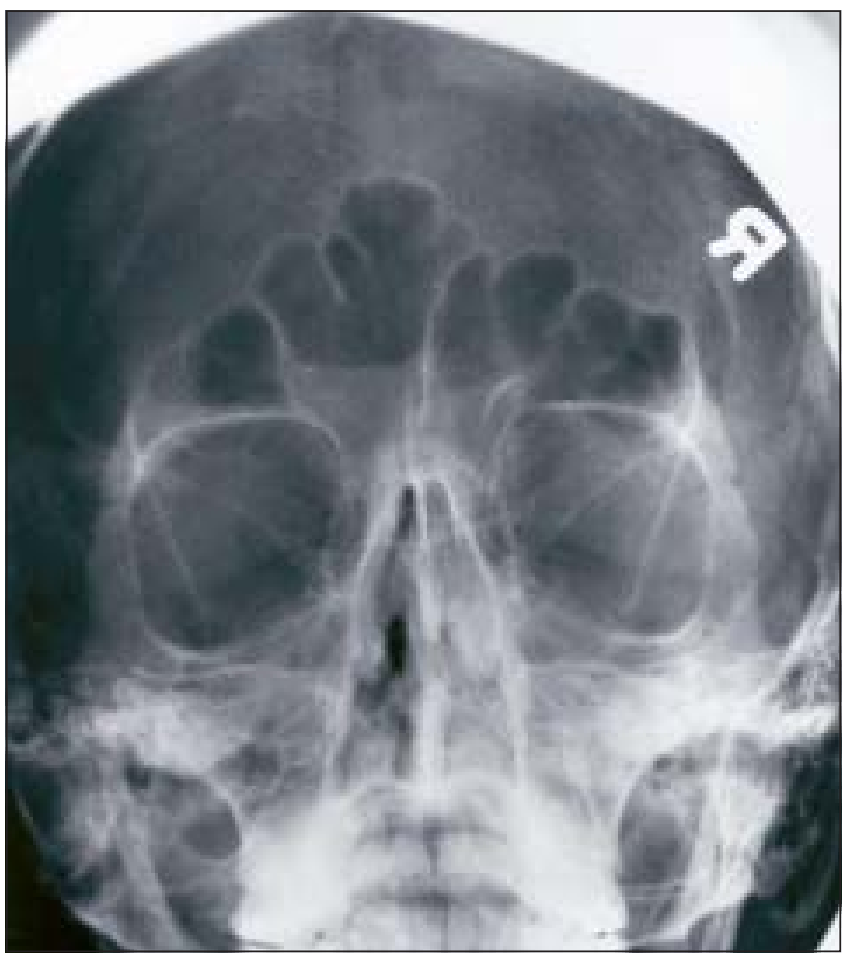

Figure 2) One view of the series of sinus radiographs taken at presentation

infection) and local wound care. Blistering and desquamation are common during the healing process.

The two unusual aspects of this patient's presentation are the sinus infection as the likely source of the erysipelas, and the lack of facial pain or pressure in the presence of such an extensive pansinusitis. When encountering a facial erysipelas without evidence of a portal of entry, a search for an underlying infectious source is mandatory. An examination of the teeth and sinuses are necessary. If no source is still evident, sinus X-rays should be completed in all such patients, regardless of symptoms.

\section{REFERENCES}

1. Jorup-Ronstrom C. Epidemiological, bacteriological and complicating features of erysipelas. Scan J Infect Dis 1986;18:519-24.

2. Evans FO, Sydnor JB, Moore WE, et al. Sinusitis of maxillary antrum. N Engl J Med 1975;293:735-9.

3. Ochs MW, Dolwick MF. Facial erysipelas: report of a case and review of the literature. J Oral Maxillofacial Surgery 1991;49:1116-20. 


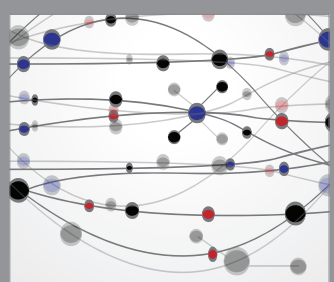

The Scientific World Journal
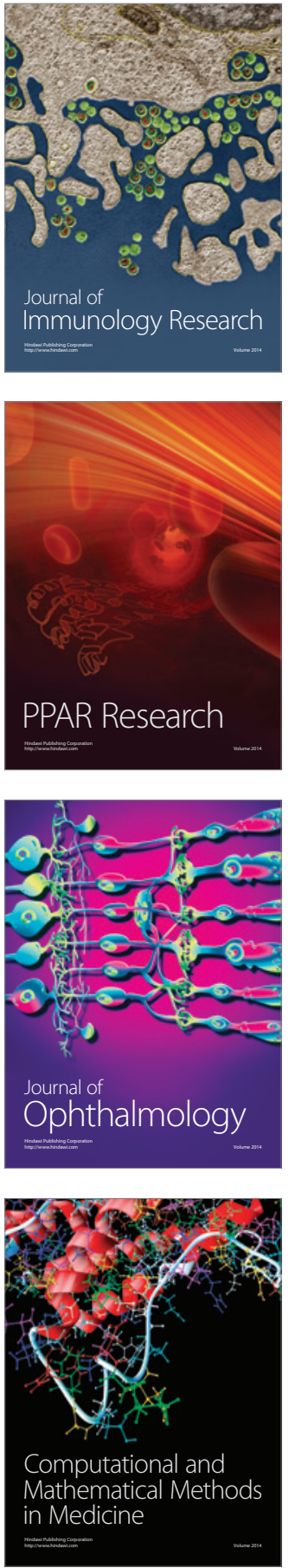

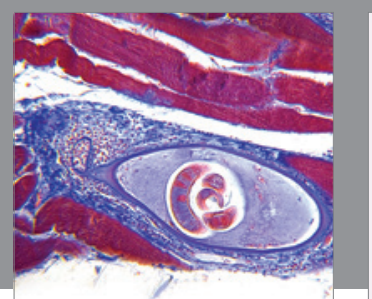

Gastroenterology Research and Practice

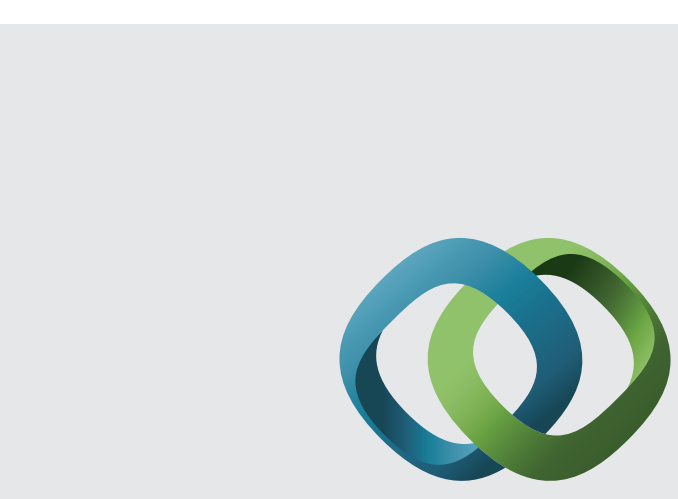

\section{Hindawi}

Submit your manuscripts at

http://www.hindawi.com
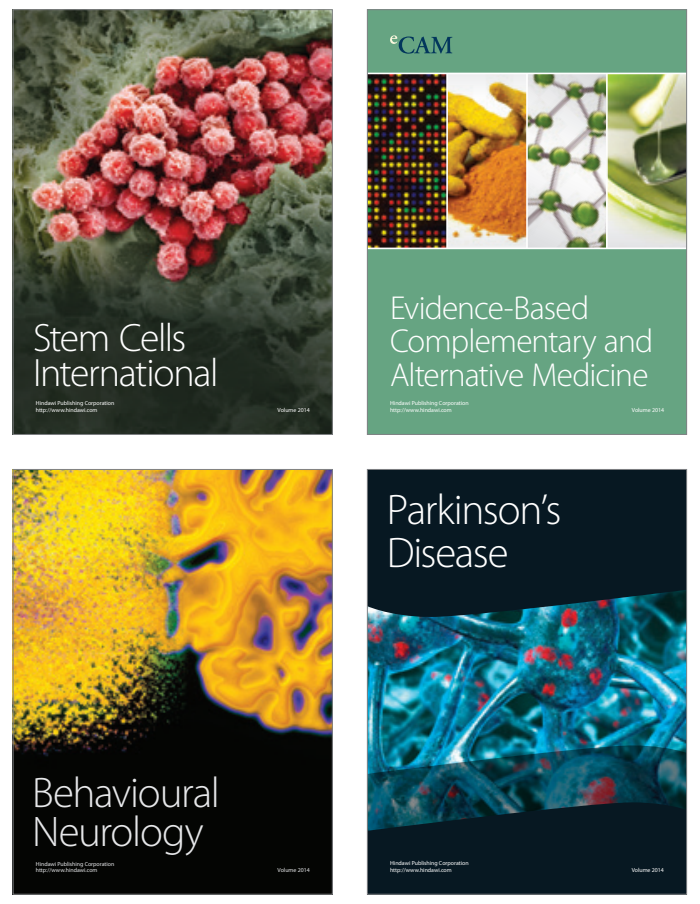
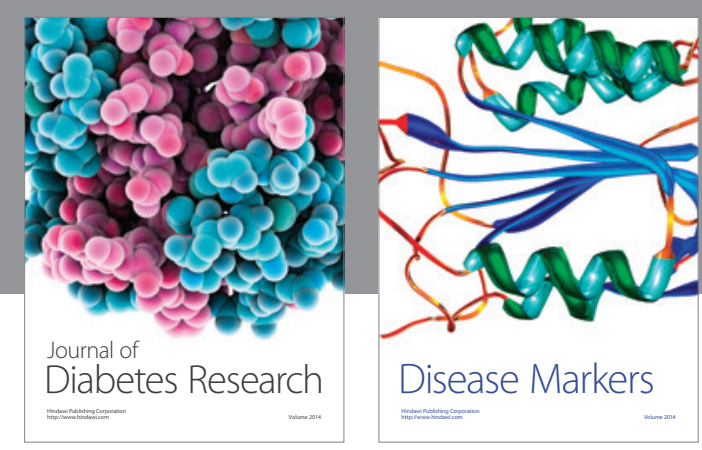

Disease Markers
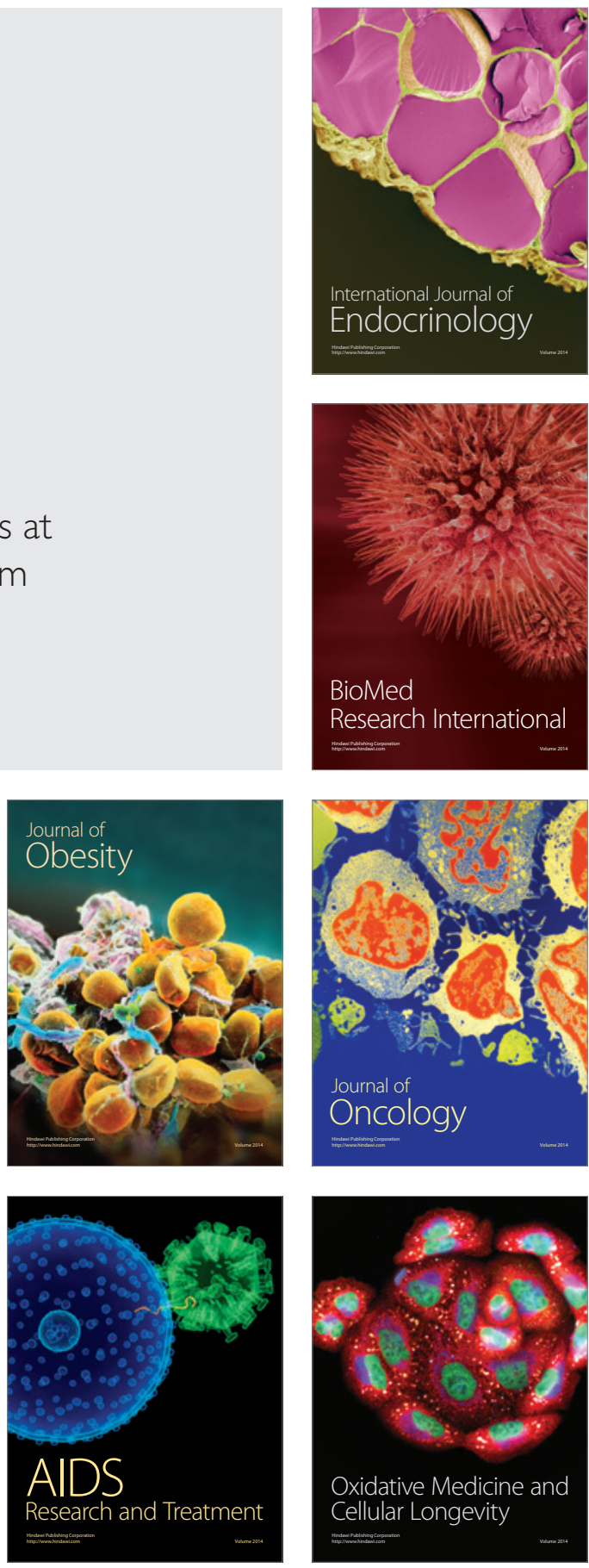